\title{
Association between Potentially Inappropriate Prescription (PIP) and Health Outcome Among Geriatric Home Residents
}

\author{
Moatassem S. Amer, Rania M. Elakkad, Alaa I. Saeed \\ Department of Geriatrics and Gerontology, Faculty of Medicine, Ain Shams University \\ Corresponding author: Alaa I. Saeed, E-mail: alaasaeed90@gmail.com, Mobile: 01005115675.
}

\begin{abstract}
Background: Appropriate prescribing of medications in elderly especially with advancing age is a major clinical and economic issue. Therefore, health care and appropriate use of medications with advancing age is one of the major challenges facing health care systems. Potentially inappropriate prescriptions (PIP) are defined by the presence of a risk of prescribed drugs that overweighs their benefit. Especially, when there are safer alternatives and include misuse of medications, prescription of drugs with significant drug-drug or drugdisease interactions and the negligence of beneficial medications.

Aim of the Study: To assess the association between potentially inappropriate prescription and health outcome among a sample of Egyptian elderly patients in geriatric homes in Cairo.

Methods: A cross-sectional study. A random sample of 120 geriatric home residents in Cairo. Demographic data were collected and comprehensive geriatric assessment was done for each participant including history taking, clinical examination, psychological, mental, functional, risk of falls and nutritional assessment. Assessment of potentially inappropriate prescription using STOPP criteria.

Results: The present study showed that among the 120 participants; the prevalence of PIP using STOPP criteria was $27(22.5 \%)$ of them were taking one or more PIP, 24 (20\%) were taking one PIP and $3(2.5 \%)$ were taking 2 PIP, $12(44.4 \%)$ of the studied participants having visual impairment were using PIP regarding STOPP criteria; 7 (25.9\%) of the studied participants having hearing impairment were using PIP as detected by STOPP criteria, so there was significant relation between PIP and patients who had visual and hearing impairments, there was a significant relation between PIP among the studied group using STOPP criteria regarding functional assessment (Instrumental activity of daily living (IADL) with p-value equal (0.031), and there was no significant relation with cognitive, psychological, risk of falls and nutritional assessment and there was no significant relation with other health outcome.

Conclusion: Potentially inappropriate prescription using STOPP criteria was found to be statistically significant with hearing, visual impairment and regarding functional assessment (IADL) only. No significant association with other health outcome.
\end{abstract}

Keywords: Potentially Inappropriate Prescription (PIP), Health outcome, Elderly, Geriatric homes.

\section{INTRODUCTION}

Elderly persons are more susceptible to the adverse medication outcomes because of the age related changes in drug pharmacokinetics and pharmacodynamics and their complex drug regimens. The risk of polypharmacy and complex medication regimens rise especially with the increased prevalence of chronic multimorbidity and symptoms in elderly ${ }^{(1)}$.

Potentially inappropriate prescriptions (PIP) are defined by the presence of a risk of prescribed drugs that overweighs their benefit, especially, when there are safer alternatives. PIP includes misuse of medications, prescription of drugs with significant drug-drug or drug-disease interactions and the negligence of beneficial medications. Potentially inappropriate prescribing is a major health care concern and is associated with polypharmacy, adverse drug events, morbidity, mortality, functional decline and substantial economic costs. Inappropriate medication prescribing for elderly patients has become one of the major issues for family physicians who manage most of the chronic diseases. Nursing home residents are particularly vulnerable to potentially inappropriate prescribing (PIP) as they are more fragile, receive therapy from multiple health care workers and are often prescribed a high number of medications. It makes prescribing in this setting a challenging task and very complex issue ${ }^{(2)}$.

For geriatric population, there is strong evidence of a sizable and consistent negative effect of inappropriate drug use on patients' health status. And an associated increase in use of outpatient services and more rapid hospitalization. Prescribing for older people is especially daunting because they require complex regimens for multiple chronic conditions. Moreover, to minimize adverse drug reactions, practitioners must consider age-related changes in drug pharmacokinetics and pharmacodynamics when selecting from the thousands of chemical entities available. Prevalence of PIP is higher in nursing home settings. A study conducted in South Africa, reported that the prevalence of PIP using Beers criteria was significantly higher 
(2.1\%) among nursing home residents as compared to community-dwelling elderly ${ }^{(3)}$.

A recent systematic review declared that up to $74 \%$ of nursing home residents were exposed to 10 or more drugs. Therefore, optimizing drug prescriptions in nursing homes is essential ${ }^{(4)}$.

Different sets of explicit criteria to measure the prevalence of potentially inappropriate prescription in nursing homes, of these sets are the Beer's criteria, Screening Tool of Older Person's Prescriptions criteria (STOPP), Screening Tool to Alert doctors to Right Treatment criteria (START), Laroche's list of criteria, McLeod criteria, the Swedish National Board of Health and Welfare criteria and Norwegian General Practice (NORGEP) criteria. A number of tools have been developed to identify PIP in many clinical settings, including the Beers criteria and STOPP/START (Screening Tool of Older Persons' potentially inappropriate Prescriptions/Screening Tool to Alert doctors to Right Treatment) ${ }^{(5,6)}$.

The STOPP/START criteria were developed by a team of geriatricians, pharmacists, pharmacologists and primary care physicians, published in 2008 and updated in 2014. The STOPP criteria include drugs to be avoided in the elderly, those that increase risk of falls, drug-drug and drug-disease interactions, and duplicate class prescriptions. The START criteria include drugs that should be used in the elderly which based on evidence for impact. The 2012 Beers criteria update has made them more similar to the STOPP/START criteria than prior iterations ${ }^{(5)}$.

The 80 STOPP and 34 START criteria are grouped by physiological system (cardiovascular system, central nervous system, etc.) and each criterion is accompanied by a brief rationale as to why a particular medication or combination of medications is considered potentially inappropriate or appropriate ${ }^{(7)}$.

\section{AIM OF THE WORK}

To assess the association between potentially inappropriate prescription and health outcome among a sample of Egyptian elderly patients in geriatric homes in Cairo.

\section{PATIENTS AND METHODS}

Design: Cross-sectional study.

Setting: Geriatric homes in Cairo.
Participants: 120 male and female elderly people were chosen through a stratified random sampling from geriatric homes in Cairo.

The study was approved by the Ethical Committee of the Faculty of Medicine, Ain Shams University. Consent was taken from all participants.

\section{All participants were subjected to:}

Comprehensive geriatric assessment including complete history taking, clinical examination, mental (MMSE). psychological (GDS). functional assessment (ADL and IADL), risk of falls(TUG), nutritional assessment (MNA). Assessment of potentially inappropriate prescription using STOPP criteria. STOPP criteria (Screening Tool of Older Person's Prescriptions). It includes sixty-eight potentially inappropriate prescribing practices in older people were presented to the panel. STOPP incorporates commonly potentially inappropriate prescribing in older people including drug-drug and drug-disease interactions, drugs which adversely affect older patients at risk of falls and duplicate drug class prescriptions. STOPP criteria are arranged according to relevant physiological systems ${ }^{(8)}$.

It was developed and validated in 2008 and include 65 indicators to identify important drug to drug, drug to disease interactions and updated in 2015 to include; drugs affecting or being affected by renal function, similar to the AGS Beers Criteria update 2015 (5).

STOPP criteria medications exhibit a high sensitivity in detecting PIMs, good inter-rater reliability and significantly associated with adverse drug events ${ }^{(9)}$.

\section{Statistical analysis}

The collected data were coded, tabulated, and statistically analyzed using IBM SPSS statistics (Statistical Package for Social Sciences) software version 23.0, IBM Corp., Chicago, USA, 2015.

The comparison between two independent groups with qualitative data was done by using Chi-square test and/or Fisher exact test only when the expected count in any cell found less than 5 . The comparison between two independent groups with quantitative data and parametric distribution was done by using Independent t-test. The 
confidence interval was set to $95 \%$ and the margin of error accepted was set to $5 \%$. So, the p-value was considered significant as the following: $\mathrm{P}>$ 0.05: Non significant. $\mathrm{P}<0.05$ : Significant. $\mathrm{P}<$ 0.01: Highly significant.

\section{RESULTS}

One hundred and twenty geriatric home residents from Egypt participated in the study. The most frequent age of the studied group was above 70 years old, the most frequent gender was female and mostly illiterate nonsmoker. Among the 120 participants, $27(22.5 \%)$ of them were taking one or more PIP, 24 (20\%) were taking one PIP and 3 (2.5\%) were taking 2 PIP. This categorization was done based on STOPP criteria (table 1).

Table (1): Prevalence of Potentially Inappropriate Prescription among the Elderly people in geriatric homes (more than 60 years old) taking at least one inappropriate medication using STOPP criteria.

\begin{tabular}{|l|l|c|c|}
\hline \multicolumn{2}{|c|}{} & $\begin{array}{c}\text { Total no. } \\
\mathbf{= 1 2 0}\end{array}$ & $\mathbf{1 0 0 \%}$ \\
\hline \multirow{3}{*}{$\begin{array}{l}\text { STOPP } \\
\text { criteria }\end{array}$} & Number of persons with No PIP by STOPP criteria & 93 & $77.5 \%$ \\
& Number of persons with $\geq 1$ PIPs & 27 & $22.5 \%$ \\
& Number of persons with 2 PIP & 24 & $20 \%$ \\
\end{tabular}

Table (2): Comparison between with and without potentially inappropriate prescription among the studied group by STOPP criteria regarding demographic characteristics.

\begin{tabular}{|c|c|c|c|c|c|c|}
\hline & $\begin{array}{l}\text { No PIP in } \\
\text { STOPP } \\
\text { Criteria }\end{array}$ & $\begin{array}{c}\text { Positive } 1 \text { or } \\
\text { more PIP in } \\
\text { STOPP criteria }\end{array}$ & \multirow[t]{2}{*}{$\begin{array}{c}\text { Test } \\
\text { value }\end{array}$} & \multirow[t]{2}{*}{$\begin{array}{c}\text { P- } \\
\text { value }\end{array}$} & \multirow[t]{2}{*}{ Sig. } \\
\hline & & No. $=93$ & No. $=27$ & & & \\
\hline \multirow[b]{2}{*}{ Age } & $\begin{array}{l}\text { Mean } \pm \text { SD } \\
\text { Range }\end{array}$ & $\begin{array}{c}70.46 \pm 6.82 \\
60-90\end{array}$ & $\begin{array}{c}72.33 \pm 8.50 \\
60-97\end{array}$ & $1.185^{\bullet}$ & 0.238 & NS \\
\hline & $\begin{array}{l}\text { From } 60 \mathrm{y} \text { to } 64 \mathrm{y} \\
\text { From } 65 \mathrm{y} \text { to } 70 \mathrm{y} \\
\text { Above } 70 \text { years }\end{array}$ & $\begin{array}{l}15(16.1 \%) \\
41(44.1 \%) \\
37(39.8 \%)\end{array}$ & $\begin{array}{c}4(14.8 \%) \\
8(29.6 \%) \\
\mathbf{1 5}(\mathbf{5 5 . 6 \% )}\end{array}$ & $2.295^{*}$ & 0.317 & NS \\
\hline Gender & $\begin{array}{l}\text { Male } \\
\text { Female }\end{array}$ & $\begin{array}{l}51(54.8 \%) \\
42(45.2 \%)\end{array}$ & $\begin{array}{l}14(51.9 \%) \\
13(48.1 \%)\end{array}$ & $0.075^{*}$ & 0.784 & NS \\
\hline Education & $\begin{array}{l}\text { Illiterate } \\
\text { Below high school } \\
\text { High school } \\
\text { Above high school }\end{array}$ & $\begin{array}{l}28(30.1 \%) \\
17(18.3 \%) \\
17(18.3 \%) \\
31(33.3 \%)\end{array}$ & $\begin{array}{l}13(48.1 \%) \\
3(11.1 \%) \\
4(14.8 \%) \\
7(25.9 \%)\end{array}$ & $3.145^{*}$ & 0.370 & NS \\
\hline Smoking & $\begin{array}{l}\text { Negative } \\
\text { positive }\end{array}$ & $\begin{array}{l}82(88.2 \%) \\
11(11.8 \%)\end{array}$ & $\begin{array}{c}21(77.8 \%) \\
6(22.2 \%)\end{array}$ & $1.859^{*}$ & 0.173 & NS \\
\hline
\end{tabular}

P-value > 0.05: Non significant; P-value < 0.05: Significant; P-value < 0.01: Highly significant; NA: Not applicable *: Chi-square test; $\bullet$ Independent t-test
Table (3): Comparison between with and without potentially inappropriate prescription among the studied group by STOPP criteria regarding comorbidities and chronic medical conditions characteristics.

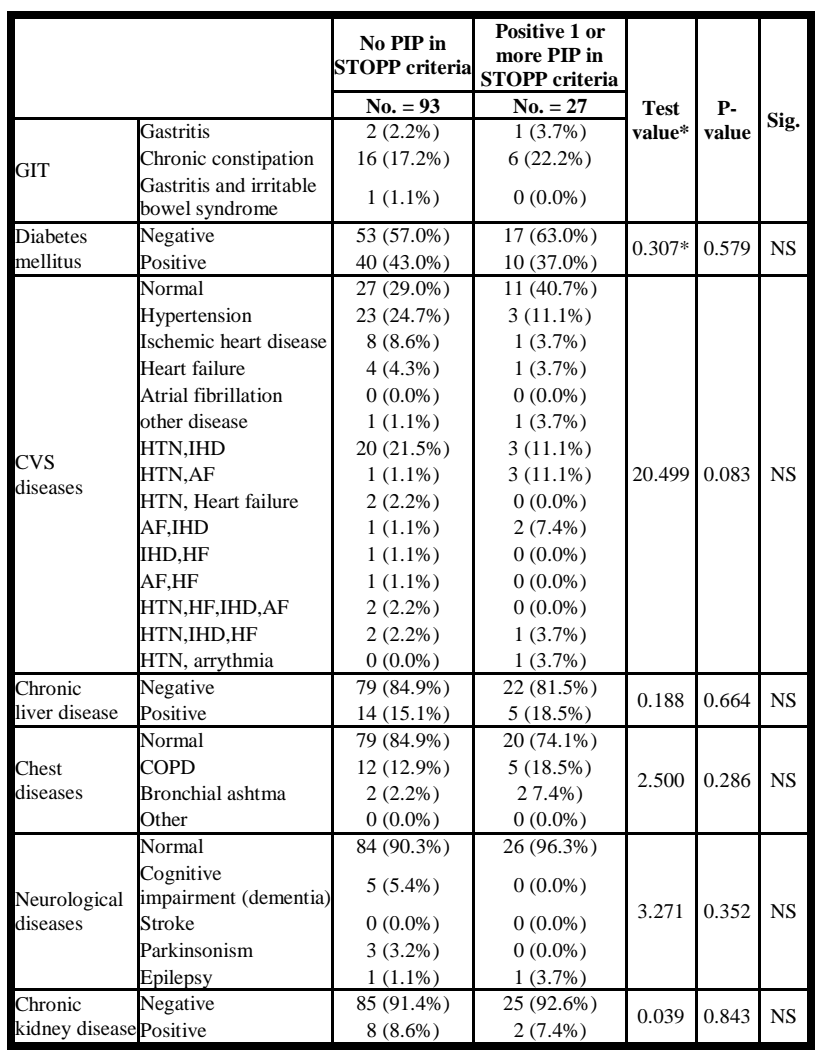

P-value > 0.05: Non significant; P-value < 0.05: Significant; P-value < 0.01: Highly significant; NA: Not applicable*: Chi-square test

Table (4): Comparison between with and without potentially inappropriate prescription among the studied group by STOPP criteria regarding other common geriatric comorbidities.

\begin{tabular}{|c|c|c|c|c|c|c|}
\hline & $\begin{array}{c}\text { No PIP in } \\
\text { STOPP criteria }\end{array}$ & $\begin{array}{c}\text { Positive } 1 \text { or } \\
\text { more PIP in } \\
\text { STOPP criteria }\end{array}$ & \multirow[t]{2}{*}{\begin{tabular}{|c|} 
Test \\
value*
\end{tabular}} & \multirow[t]{2}{*}{$\begin{array}{c}\text { P- } \\
\text { value }\end{array}$} & \multirow[t]{2}{*}{ Sig. } \\
\hline & & No. $=93$ & No. $=27$ & & & \\
\hline Incontinence & \begin{tabular}{|l|} 
Negative \\
Positive (urinary)
\end{tabular} & $\begin{array}{c}92(98.9 \%) \\
1(1.1 \%)\end{array}$ & $\begin{array}{c}27(100.0 \%) \\
0(0.0 \%)\end{array}$ & 0.293 & 0.588 & NS \\
\hline Osteoporosis & \begin{tabular}{|l} 
Negative \\
Positive
\end{tabular} & $\begin{array}{c}90(96.8 \%) \\
3(3.2 \%)\end{array}$ & $\begin{array}{c}27(100.0 \%) \\
0(0.0 \%)\end{array}$ & 0.893 & 0.345 & NS \\
\hline Falls & \begin{tabular}{|l} 
Negative \\
Positive
\end{tabular} & $\begin{array}{l}81(87.1 \%) \\
12(12.9 \%)\end{array}$ & $\begin{array}{c}26(96.3 \%) \\
1(3.7 \%)\end{array}$ & 1.833 & 0.176 & NS \\
\hline $\begin{array}{l}\text { Visual } \\
\text { impairment }\end{array}$ & \begin{tabular}{|l|} 
No impairment \\
Positive \\
\end{tabular} & $\begin{array}{l}70(75.3 \%) \\
23(24.7 \%) \\
\end{array}$ & $\begin{array}{l}15(55.6 \%) \\
12(44.4 \%) \\
\end{array}$ & 3.936 & 0.047 & S \\
\hline $\begin{array}{l}\text { Hearing } \\
\text { impairment }\end{array}$ & $\begin{array}{l}\text { No impairment } \\
\text { Positive }\end{array}$ & $\begin{array}{l}83(89.2 \%) \\
\mathbf{1 0}(\mathbf{1 0 . 8 \% )}\end{array}$ & $\begin{array}{l}20(74.1 \%) \\
7(25.9 \%) \\
\end{array}$ & 3.962 & 0.047 & $\mathrm{~s}$ \\
\hline $\begin{array}{l}\text { Surgical } \\
\text { procedures }\end{array}$ & \begin{tabular}{|l|} 
Negative \\
Major operations \\
Minor operations \\
\end{tabular} & $\begin{array}{c}85(91.4 \%) \\
7(7.7 \%) \\
1(1.1 \%) \\
\end{array}$ & $\begin{array}{c}27(100.0 \%) \\
0(0.0 \%) \\
0(0.0 \%) \\
\end{array}$ & 2.488 & 0.870 & NS \\
\hline Hospitalization & \begin{tabular}{|l|} 
Negative \\
Positive \\
\end{tabular} & $\begin{array}{l}83(89.2 \%) \\
10(10.8 \%)\end{array}$ & $\begin{array}{c}25(92.6 \%) \\
2(7.4 \%)\end{array}$ & 0.260 & 0.610 & NS \\
\hline $\begin{array}{l}\text { Polypharmacy } \\
\text { ( } \geq 5 \text { drugs) }\end{array}$ & \begin{tabular}{|l}
$\begin{array}{l}\text { Negative } \\
\text { Positive }\end{array}$ \\
\end{tabular} & $\begin{array}{l}55(59.1 \%) \\
38(40.9 \%)\end{array}$ & $\begin{array}{l}16(59.3 \%) \\
11(40.7 \%)\end{array}$ & 0.000 & 0.991 & NS \\
\hline $\begin{array}{l}\text { Benign prostatic } \\
\text { hyperplasia }\end{array}$ & $\begin{array}{l}\text { Negative } \\
\text { Positive }\end{array}$ & $\begin{array}{l}80(86.0 \%) \\
13(14.0 \%)\end{array}$ & $\begin{array}{c}21(77.8 \%) \\
6(22.2 \%)\end{array}$ & 1.067 & 0.302 & NS \\
\hline Osteoarthritis & $\begin{array}{l}\text { Negative } \\
\text { Positive }\end{array}$ & $\begin{array}{l}61(65.6 \%) \\
32(34.4 \%)\end{array}$ & $\begin{array}{l}12(44.4 \%) \\
15(55.6 \%)\end{array}$ & 4.524 & 0.104 & NS \\
\hline
\end{tabular}

$\mathrm{P}$-value > 0.05: Non significant; $\mathrm{P}$-value < 0.05: Significant; P-value < 0.01: Highly significant; NA: Not applicable *: Chi-square test+ 
Table (5): Comparison between with and without potentially inappropriate prescription among the studied group by STOPP criteria regarding Cognitive, Psychological, Functional, Risk of Falls and Nutritional assessment.

\begin{tabular}{|c|c|c|c|c|c|c|}
\hline & $\begin{array}{c}\text { no PIP in } \\
\text { STOPP } \\
\text { criteria }\end{array}$ & \begin{tabular}{|c|} 
Positive 1 or \\
more PIP in \\
STOPP criteria \\
\end{tabular} & \multirow[t]{2}{*}{$\begin{array}{c}\text { Test } \\
\text { value }\end{array}$} & \multirow[t]{2}{*}{ P-value } & \multirow[t]{2}{*}{ Sig } \\
\hline & & No. $=93$ & No. $=27$ & & & \\
\hline \begin{tabular}{|l|} 
Mini Mental \\
State examination \\
\end{tabular} & \begin{tabular}{|l|} 
Mean \pm SD \\
Range \\
\end{tabular} & \begin{tabular}{|c|}
$26.26 \pm 4.23$ \\
$16-30$ \\
\end{tabular} & $\begin{array}{c}25.52 \pm 3.98 \\
17-30 \\
\end{array}$ & $-0.810 \bullet$ & 0.420 & NS \\
\hline $\begin{array}{l}\text { Cognitive } \\
\text { function }\end{array}$ & \begin{tabular}{|l|} 
Normal cognitive \\
Function \\
Mild cognitive \\
impairment \\
Moderate to \\
severe cognitive \\
impairment \\
\end{tabular} & $\begin{array}{l}61(65.6 \%) \\
22(23.7 \%) \\
10(10.8 \%)\end{array}$ & $\begin{array}{l}16(59.3 \%) \\
9(33.3 \%) \\
2(7.4 \%)\end{array}$ & $1.124^{*}$ & 0.570 & NS \\
\hline \begin{tabular}{|l|} 
Geriatric \\
Depression Scale
\end{tabular} & \begin{tabular}{|l|} 
Normal \\
Suggestive \\
Positive depression \\
\end{tabular} & $\begin{array}{c}68(73.1 \%) \\
22(23.7 \%) \\
3(3.2 \%) \\
\end{array}$ & $\begin{array}{c}17(63.0 \%) \\
9(33.3 \%) \\
1(3.7 \%)\end{array}$ & $1.078^{*}$ & 0.583 & NS \\
\hline $\begin{array}{l}\text { Activity of } \\
\text { daily living }\end{array}$ & \begin{tabular}{|l|} 
Independent \\
Assisted \\
Dependent \\
\end{tabular} & $\begin{array}{c}84(90.3 \%) \\
7(7.5 \%) \\
2(2.2 \%) \\
\end{array}$ & $\begin{array}{c}23(85.2 \%) \\
3(11.1 \%) \\
1(3.7 \%) \\
\end{array}$ & $0.586^{*}$ & 0.746 & NS \\
\hline $\begin{array}{l}\text { Instrumental } \\
\text { activity of } \\
\text { daily living } \\
\end{array}$ & \begin{tabular}{|l|} 
Independent \\
Assisted \\
Dependent \\
\end{tabular} & $\begin{array}{l}45(48.4 \%) \\
34(36.6 \%) \\
14(15.1 \%) \\
\end{array}$ & $\begin{array}{c}20(74.1 \%) \\
3(11.1 \%) \\
4(14.8 \%) \\
\end{array}$ & $6.945^{*}$ & 0.031 & $\mathrm{~S}$ \\
\hline $\begin{array}{l}\text { Timed Up } \\
\text { and Go test } \\
\end{array}$ & $\begin{array}{l}\text { no risk of falls } \\
\text { risk of falls }\end{array}$ & $\begin{array}{l}42(45.2 \%) \\
51(54.8 \%) \\
\end{array}$ & $\begin{array}{c}9(33.3 \%) \\
18(66.7 \%) \\
\end{array}$ & $1.198^{*}$ & 0.274 & NS \\
\hline $\begin{array}{l}\text { Mini Nutritional } \\
\text { Assessment }\end{array}$ & $\begin{array}{l}\text { No risk } \\
\text { At risk of } \\
\text { malnutrition } \\
\end{array}$ & $\begin{array}{l}77(82.8 \%) \\
16(17.2 \%)\end{array}$ & $\begin{array}{l}23(85.2 \%) \\
4(14.8 \%)\end{array}$ & $0.086^{*}$ & 0.769 & NS \\
\hline
\end{tabular}

\section{DISCUSSION}

The prevalence of potentially inappropriate prescription (PIP) among the studied sample in geriatric homes in Egypt using STOPP criteria was 22.5\%.

According to STOPP, criteria number of elderly with one or more PIP were 27 presenting $(22.5 \%)$ of the studied sample, elderly with one PIP were 24 (20\%) and elderly with two PIP by STOPP criteria were $3(2.5 \%)$. As shown in table (1).

According to many studies conducted among different countries, found that the prevalence of potentially inappropriate medication use in the elderly people which frequently observed in the nursing home setting range from $23.7 \%$ up to $70 \%{ }^{(24)}$.

Another study done by Klejda et al. ${ }^{(10)}$ included six hundred twenty four co-morbid older patients at hospital discharge after applying the exclusion criteria, found that the prevalence of PIPs according to Beers criteria was $(22.9 \%)$, whereas according to STOPP criteria was (38.5\%).

The prevalence of PIP is higher in nursing home settings. A study conducted in South Africa, reported that the prevalence of PIP using Beers criteria was significantly higher $(2.1 \%)$ among nursing home residents as compared to communitydwelling elderly Chetty et al. ${ }^{(3)}$.

The higher prevalence of PIP in nursing home settings can be explained by that nursing home residents are generally more vulnerable than other elderly groups when it comes to receiving PIPs. This can be explained by the frail condition of the residents besides being prescribed with multiple medications due to multiple comorbidities which increased the risk of drug interactions and prescribing cascades Beers et al. ${ }^{(11)}$.

This high prevalence was found by Jokanovic et $\boldsymbol{a l} .{ }^{(4)}$ which declared that up to $74 \%$ of nursing home residents were exposed to 10 or more drugs, as a polypharmacy and PIP, therefore, optimizing drug prescriptions in nursing homes is essential.

The current study showed that, $55.6 \%$ of elderly above 70 years had PIP while only $39.8 \%$ of elderly above 70 years had no PIP, but this was not statistically significant. As shown in table (2), and there was no significant association between using one or more PIP with gender, education and smoking.

Another study done by Galvin et al. ${ }^{(12)}$ found that no association between PIP and gender after adjustment for age.

We found no statistically significant difference between elderly with one or more potentially inappropriate prescription and those without PIP by the STOPP criteria regarding multiple comorbidities and polypharmacy assed in this study. As shown in tables (3).

This is inconsistent with Galvin et al. ${ }^{(12)}$ who declared that there is a significant association between comorbidities and polypharmacy and number of potentially inappropriate medications.

This was not supported by a study done by Marie et al. ${ }^{(13)}$ found that the prevalence of polypharmacy was $24.3 \%$ and there was high statistical significance between PIPs, polypharmacy and hospitalization in people living in nursing homes

There was no statistically significant difference between elderly with PIP by STOPP criteria and those with no PIP regarding functional, cognitive, nutritional and risk of falls.

This was also found in Gnjidic et al. ${ }^{(14)}$ found that no association between PIPs uses assessed by Beers criteria and functional outcomes in immediate-level residential aged care facilities in 
Australia. Similarly, Hanlon et al. ${ }^{(15)}$ found no association between PIPs use and decline in functional status in the Duke Established Populations for Epidemiologic Studies of the Elderly cohort in the United States.

These findings were not supported by some studies, which have demonstrated increased levels of falls with increasing levels of PIPs Wilson et al. ${ }^{(16)}$.

Also, a study conducted by Leikola et al. ${ }^{(17)}$ found that the frequency of potentially inappropriate medications using Beers criteria, had a significant association with functional, cognitive and risk of falls among the elderly participants in Finland and this was similar to a study done by Landi et al. ${ }^{(18)}$.

On the other hand, Landi et al. ${ }^{(19)}$ declared that, despite the high exposure to PIPs ranging from $10.2 \%$ to $56.4 \%$ and this variation in occurrence of PIPs may be explained by difference in assessment of PIPs, study design, settings and population characteristics; cognitive impairment and dementia were associated with a lower probability of PIP in most studies. No study reported a positive association between cognitive impairment or dementia and PIP. However, the same criteria for PIP were used for patients with and without cognitive impairment or dementia, although there may be a difference in which medications that should be regarded as appropriate or inappropriate in these two groups (20). So, cognitive impairment often found to be associated with a decrease in the use of potentially inappropriate prescription (PIP).

Perri et al. (21) suggest that possible explanations include physicians' vigilance in prescribing to patients with reduced cognitive capacity in fear of further cognitive impairment from adverse drug effects.

In the current study we found that elderly with both hearing and visual impairment were susceptible more to PIP, as it was found that $25.9 \%$ of elderly with hearing impairment and $44.4 \%$ with visual impairment had PIP by STOPP criteria, while only $10.8 \%$ with hearing impairment and $24.7 \%$ with visual impairment had no PIP, and this was of statistical significance as shown in table (5). By reviewing other literature this finding was not discussed in previous studies.

The findings of nearly quarter of the residents were exposed to potentially inappropriate prescription need further attention. Further studies with larger sample size are recommended to assess association between PIP and health outcome among geriatric elderly.

\section{CONCLUSION}

Potentially inappropriate prescription (PIP) is highly prevalent among older residents living in the nursing homes. The prevalence of PIP was $22.5 \%$ according to STOPP criteria among a sample of Egyptian elderly patients in geriatric homes. PIP using STOPP criteria was found to be statistically significant with hearing and visual impairment. Polypharmacy, chronic medical diseases and common geriatric conditions were of no statistical significance with PIP using STOPP criteria. Geriatric domains (cognition, psychological, nutritional and fall risk) were of no statistical significance with PIP using STOPP criteria, except functional (IADL) was statistically significant with PIP using STOPP criteria.

\section{REFERENCES}

1. Moore KL, Boscardin WJ, Steinman MA et al. (2014): Patterns of Chronic Co-Morbid Medical Conditions in Older Residents of Us Nursing Homes: Differences between the Sexes and across the Agespan. The Journal of Nutrition, Health \& Aging, 18(4): 429-36.

2. O'Sullivan D, O'Mahony D, O'Connor MN et al. (2014): The Impact of a Structured Pharmacist Intervention on the Appropriateness of Prescribing in Older Hospitalized Patients. Drugs \& Aging, 31(6): 471-81.

3. Chetty $R$ and Gray A (2004): Inappropriate Prescribing in an Elderly Population: Findings from a South African Public Sector Survey. International Journal of Pharmacy Practice, 12(3): 149-54.

4. Jokanovic N, Tan EC, Dooley MJ et al. (2015): Prevalence and Factors Associated with Polypharmacy in Long-Term Care Facilities: A Systematic Review. Journal of the American Medical Directors Association, 16(6): 535-542.

5. O'mahony D, O'sullivan D, Byrne $\mathrm{S}$ et al. (2015): Stopp/Start Criteria for Potentially Inappropriate Prescribing in Older People: Version 2. Age Ageing, 44 (2): 213-8.

6. American Geriatrics Society Beers Criteria Update Expert Panel (2012): American Geriatrics Society Updated Beers Criteria for Potentially Inappropriate Medication Use in Older Adults. J Am Geriatr Soc., 60(4): 616-31. 
7. Luo R, Scullin C, Mullan AM et al. (2012): Comparison of Tools for the Assessment of Inappropriate Prescribing in Hospitalized Older People. Journal of Evaluation in Clinical Practice, 18(6): 1196-202.

8. Gallagher P, Ryan C, Byrne $S$ et al. (2008): STOPP (Screening Tool of Older Person's Prescriptions) and START (Screening Tool to Alert doctors to Right Treatment). Consensus validation. International Journal of Clinical Pharmacology and Therapeutics, 46(2): 72-83.

9. Ryan C, O'Mahony D, O'Donovan DÓ et al. (2013): A Comparison of the Application of Stopp/Start to Patients' Drug Lists with and without Clinical Information. International Journal of Clinical Pharmacy, 35(2): 230-35.

10. Hudhra K, Beçi E, Petrela E et al. (2016): Prevalence and Factors Associated with Potentially Inappropriate Prescriptions among Older Patients at Hospital Discharge. Journal of Evaluation in Clinical Practice, 22(5): 70713.

11. Beers MH, Ouslander JG, Rollingher I et al. (1991): Explicit Criteria for Determining Inappropriate Medication Use in Nursing Home Residents. Archives of Internal Medicine, 151(9): 1825-32.

12. Galvin R, Moriarty F, Cousins $G$ et al. (2014): Prevalence of Potentially Inappropriate Prescribing and Prescribing Omissions in Older Irish Adults: Findings from the Irish Longitudinal Study on Ageing Study (Tilda). European Journal of Clinical Pharmacology, 70(5): 599-606.

13. Herr M, Grondin H, Sanchez S et al. (2017): Polypharmacy and Potentially Inappropriate Medications: A Cross-Sectional Analysis among 451 Nursing Homes in France. Eur J Clin Pharmacol., 73(5): 601-08.

14. Gnjidic D, Bell JS, Hilmer SN et al. (2012): Drug Burden Index Associated with Function in Community-Dwelling Older People in Finland: A Cross-Sectional Study. Annals of Medicine, 44(5): 458-67.

15. Hanlon JT, Schmader KE, Boult C et al. (2002): Use of Inappropriate Prescription Drugs by Older People. Journal of the American Geriatrics Society, 50(1): 26-34.
16. Wilson NM, Hilmer SN, March LM et al. (2011): Associations between Drug Burden Index and Falls in Older People in Residential Aged Care. Journal of the American Geriatrics Society, 59(5): 875-80.

17. Dimitrow MS, Airaksinen MS, Kivelä SL $e t$ al. (2011): Comparison of Prescribing Criteria to Evaluate the Appropriateness of Drug Treatment in Individuals Aged 65 and Older: A Systematic Review. Journal of the American Geriatrics society, 59(8): 1521-30.

18. Landi F, Russo A, Liperoti $R$ et al. (2007): Impact of Inappropriate Drug Use on Physical Performance among a Frail Elderly Population Living in the Community. European Journal of Clinical Pharmacology, 63(8): 791-99.

19. Morin L, Fastbom J, Laroche ML et al. (2015): Potentially Inappropriate Drug Use in Older People: A Nationwide Comparison of Different Explicit Criteria for Population - Based Estimates. British Journal of Clinical Pharmacology, 80(2): 315-24.

20. Holmes HM, Sachs GA, Shega JW et al. (2008): Integrating Palliative Medicine into the Care of Persons with Advanced Dementia: Identifying Appropriate Medication Use. Journal of the American Geriatrics Society, 56(7): 1306-11.

21. Perri M, Menon AM, Deshpande AD et al. (2005): Adverse Outcomes Associated with Inappropriate Drug Use in Nursing Homes. Annals of Pharmacotherapy, 39(3): 405-11. 